\title{
25. REMANENT MAGNETIZATION AND MAGNETIC MINERALOGY IN DSDP LEG 37 OCEANIC BASALTS
}

\author{
E.J. Schwarz and Y. Fujiwara, Geological Survey of Canada, Ottawa, Canada
}

\begin{abstract}
Three groups of samples-(I: collected near the top of the basaltic layer at Site 335 (185 km from ridge); II: taken at 500 meters depth, Hole 332B (31 km from ridge); and III: taken at 600 meters depth, Hole 332B)-were used in natural remanence (groups I and III) and thermomagnetic (all groups) studies. Remanent magnetization of Group I is reversed with inclination (up) of about $62^{\circ}$ which is about $7^{\circ}$ higher than the present field inclination (down) in the sampled area. These samples have homogeneous magnetic mineralogy composed of probably somewhat oxidized titanomagnetites with Curie points around $360^{\circ} \mathrm{C}$. In contrast, Group III samples have lower remanent intensity, low inclination of about $30^{\circ}$ up and down, and thermomagnetic curves suggesting coexisting magnetic phases possibly varying in oxidation state and carrying different remanent components.
\end{abstract}

\section{INTRODUCTION}

The banded magnetic anomaly pattern over the oceans has been related to alternating polarity of the remanent magnetization of the spreading oceanic crust (e.g., Vine and Matthews, 1963). The decreasing amplitude of the anomaly pattern with distance from a spreading ridge is accompanied by a general increase in Curie points suggesting gradual oxidation of the original titanomagnetites and concurrent decrease in remanent intensity (Schaeffer and Schwarz, 1970). Ozima et al. (1974) suggested that seawater plays a major role in the oxidation. Laboratory experiments show that temperature may also be a factor in the oxidation. It would thus be of great interest to assess the effect of the oxidation with depth so as to obtain better models for the quantitative interpretation of the anomalies. Leg 37 of the Deep Sea Drilling Project provided an opportunity to investigate this effect.

\section{REMANENT MAGNETIZATION}

Samples from Hole 332B (31 km from ridge) and Site 335 (185 km from ridge) were suitable for the determination of direction and intensity of the natural remanent magnetization (NRM). The holes were probably drilled essentially vertically so that the inclination of the original remanent magnetization should be representative of the inclination of the local geomagnetic field at the time of cooling of the basalt. As the core was not oriented, declination values are unknown and can only be given with respect to an arbitrary direction for each section of core. Thus, successive sections of the same core are expected to differ systematically in declination if the within-section magnetization is homogeneous.

The NRM directions are plotted on a stereographic diagram as shown on Figure 1. The 10 usable samples from the upper few meters of basalt (below $450 \mathrm{~m}$ of sediment) at Site 335 form a good cluster and point upwards with average inclination $62^{\circ}$. This is about $7^{\circ}$ higher than the present geomagnetic inclination in the area and indicates magnetization acquired during a period of reversed field polarity. The results for the samples taken at 500 meters below the sediments (thickness $140 \mathrm{~m}$ ) in Hole 332B show surprisingly low inclinations of about $30^{\circ}$ both up and downwards.

Figure 2 shows that the intensity of magnetization of the deep samples from Hole 332B is on the average substantially lower than that for the near-surface samples from Site 335. On the other hand, the total capacity of magnetization as indicated by the value of the saturation magnetization at $20^{\circ} \mathrm{C}$ is on the average somewhat higher for the 332B samples. It follows that the relatively low NRM intensity of the 332B samples is probably due to partial replacement of the original high-intensity thermoremanent magnetization by magnetization components which have been acquired, for instance, during gradual oxidation (chemical remanent magnetization).

\section{MAGNETIC MINERALOGY}

Thermomagnetic curves were obtained for all samples using a recording magnetic force balance. In general, the curves are irreversible, showing an increase in Curie temperature during heating and reappearance of the magnetization at higher temperatures (Figure 3). The shape of the heating curve depends to a large extent on the ratio of the rate of increase of the Curie temperature due to progressive oxidation and the heating rate of the sample (constant at $7.5^{\circ} \mathrm{C} / \mathrm{min}$ ). Thus, there is a possibility that Curie points given in Chapters 2 and 5 (this volume) are somewhat too high. However, in cases where an apparently normal decrease in magnetization changes abruptly to a rapid increase, the Curie temperatures read from the curve probably are too low. The temperature at which the minimum in the thermomagnetic curve occurs may not represent the 


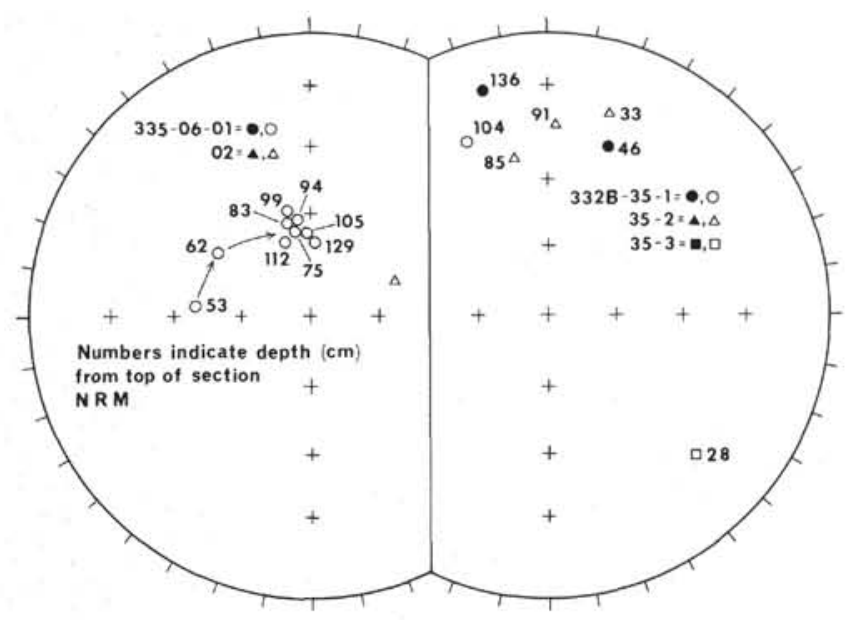

Figure 1. Stereographic diagram showing inclination of NRM. Different sections have different symbols. Open symbols indicate upper hemisphere projections.

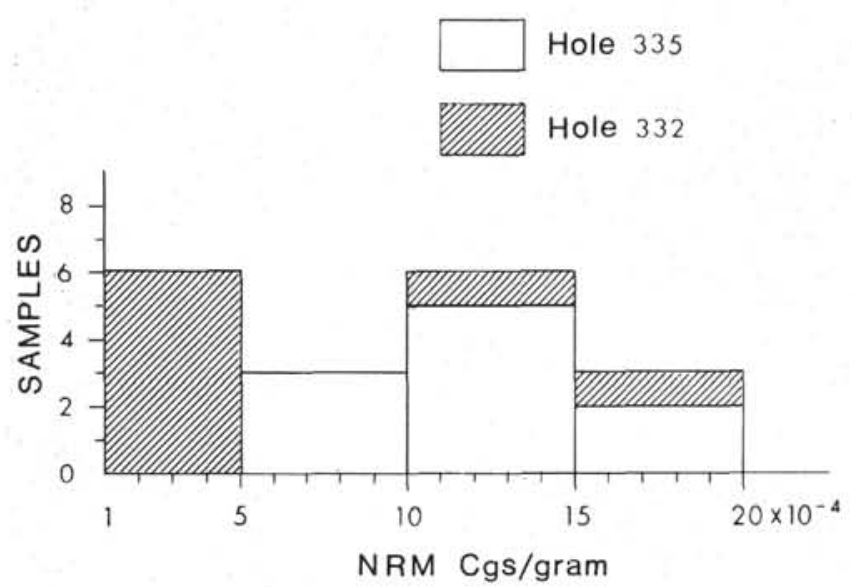

Figure 2. Intensity of NRM.

Curie temperature because (1) the apparently normal decrease just below that temperature is in part due to destruction of the original mineral, and (2), in particular, the part of the expected magnetization curve just above that temperature is masked by the effect of the rapidly increasing contribution of the oxidation products (Figures $3 \mathrm{~A}$ and $\mathrm{C}$ ).

The Curie temperature data can be divided into three groups as shown in Chapters 2 and 5 (this volume). Samples from the upper part of Site 335 yield intermediate Curie temperatures of about $360^{\circ} \mathrm{C} \pm 40$. With one possible exception, the magnetization is almost completely lost at the Curie temperature (Figure 3A), indicating that the magnetic mineralogy is reasonably homogeneous in composition. The Curie temperatures are substantially higher than those observed for very young ridge basalts (e.g., as low as $60^{\circ} \mathrm{C}$, Schaeffer and Schwarz, 1970) suggesting some oxidation of the original titanomagnetites. This homogeneous group of samples also yielded well-grouped NRM directions with plausible inclinations (Figure 1).

The eight samples collected at a depth of approximately 500 meters in Hole 332B in general show characteristics similar to the 12 samples from the top of Site 335 with the exception of a substantially lower
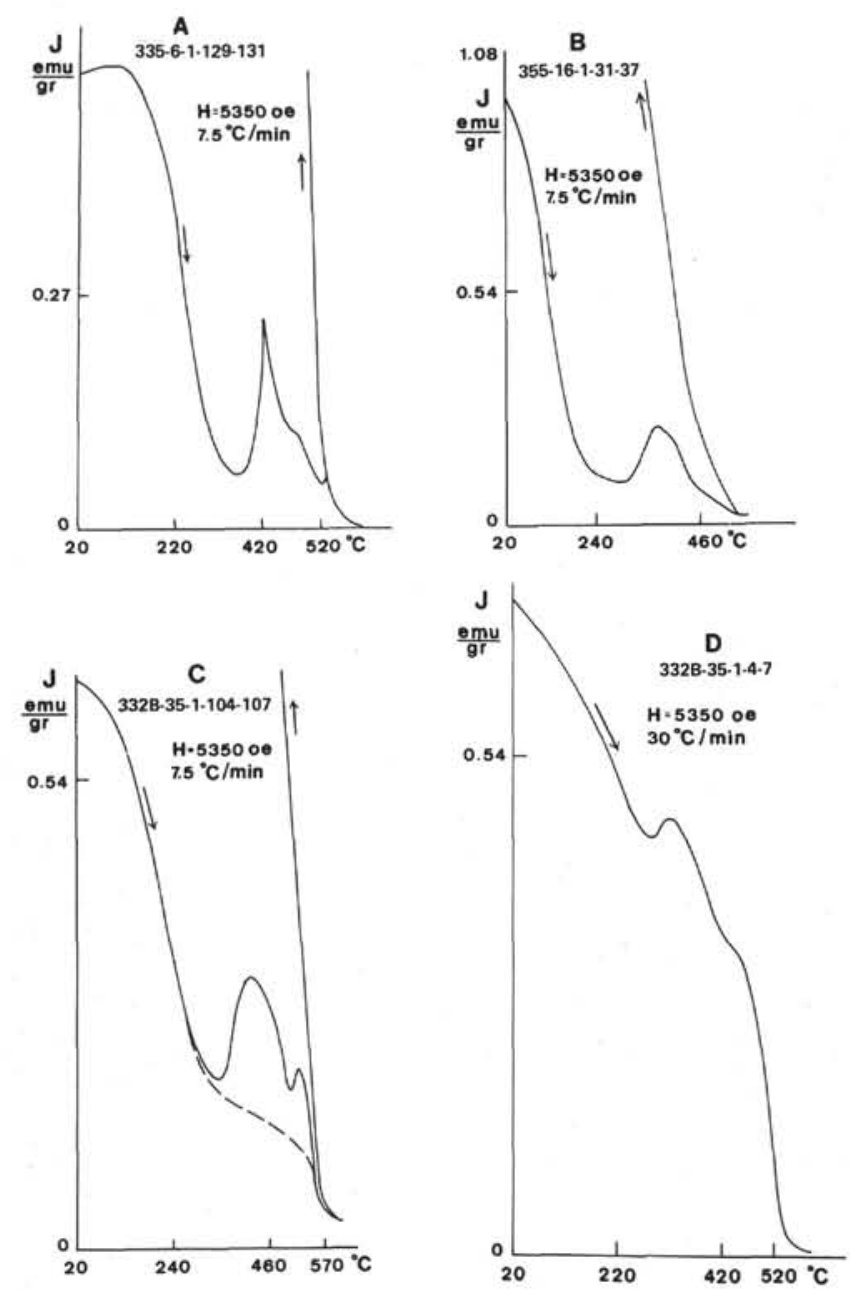

Figure 3. Change in magnetization $(\mathrm{J})$ with heating for representative samples as discussed in text. Applied field $(\mathrm{H})$ and heating rate are indicated.

average Curie temperature of about $240^{\circ} \mathrm{C} \pm 40$ (Figure 3B, Table 1). Consequently, some oxidation of the original titanomagnetite probably has occurred.

The third group is formed by eight samples collected at about 600 meters in Hole 332B. Initial Curie temperatures vary widely from, say, $240^{\circ}$ to $360^{\circ} \mathrm{C}$. However, in almost all cases the magnetization remaining after the initial Curie temperature has been exceeded is much too high to be ascribed to paramagnetics (Figures $3 \mathrm{c}$ and d). Thus, in spite of complications due to oxidation during heating, it is probable that a part of the magnetic minerals in these samples is in a more advanced stage of oxidation showing a second, higher, Curie temperature. Estimates of higher Curie temperatures are also given in Chapter 2 (this volume) The magnetic mineralogy is not homogeneous in composition. This observation suggests the coexistence of remanence components possibly of different ages in these samples. A higher oxidation state for this group as compared to the group of samples collected 100 meters up in the hole cannot be ascribed to only an effect of temperature on the rate of oxidation in nature. A general picture of the variation of the Curie temperature may emerge once the thermo- 
magnetic data on all DSDP samples have been put together.

\section{REFERENCES}

Ozima, M., Joshima, M., and Kinoshita, H., 1974. Magnetic properties of submarine basalts and the implications on the structure of the oceanic crust: J. Geomag. Geoelec., v. 26, p. $335-354$.

Schaeffer, R.M. and Schwarz, E.J., 1970. The Mid-Atlantic Ridge near $45^{\circ} \mathrm{N}$ : Thermomagnetics of dredged samples of igneous rocks: Canadian J. Earth Sci., v. 7, p. 268-273.

Vine, F.J. and Matthews, P.H., 1963. Magnetic anomalies over oceanic ridges: Nature, v. 199, p. 947-949. 